\title{
Properly equipping our teachers for the future: re-reading research in practice as an everyday habit of professional practice
}

\author{
Alex Kendall \\ University of Wolverhampton \\ WMCETT
}

\author{
Margaret Herrington \\ University of Wolverhampton
}

\begin{abstract}
In this article we make the case that Research in Practice (RiP) is intrinsic to the role of the professional teacher and as such should be an ongoing (supported) entitlement for all teachers throughout their career trajectory. This is not in itself a new call; what is different is our contention that the current policy context of post-compulsory education makes such demands more urgent, more purposeful and, crucially, of new pedagogical significance. We argue that the consequences of Equipping our Teachers for the Future (DfES, 2004) may be highly restrictive for teacher educators and the teachers they work with. We consider how RiP might facilitate new vantage points from the lived experience of working in the sector, and how the latter might be (re)viewed. We go on to suggest that RiP may also yield important pedagogical benefits for teachers and their communities, as well as contributing to knowledge and understanding about the sector more broadly. In conclusion we argue that teacher educators must take seriously the responsibility to nurture RiP as an everyday habit of professionalism and to give serious thought to providing spaces and places for RiP. We ask whether the new opportunities provided by the Institute for Learning framework can be exploited to support longitudinal research practices.
\end{abstract}

\section{Key words}

Research in Practice; Teacher Education; Professionalism; Critical Pedagogy; Professional Education.

\section{Introduction}

In this paper we argue for a formalisation of the function of RiP within initial and ongoing professional education. We use the term RiP here to mean research by practitioners within and around their own practice and experience. It can be seen as developing within action research traditions (Winter, 1989) and is thus capable of challenging the power relations within traditional forms of research. Horsman and Woodrow (2006) have recently sought to clarify its distinguishing features and note it is neither a monolithic form of action research nor one which is in all respects unproblematic.

Here, our arguments for RiP are primarily concerned with understanding RiP as a central process of critical professional education. We argue that the current policy context of post-compulsory education has made the need to attend to critical forms of education more urgent.

We challenge teacher educators to be concerned with creating spaces, most especially within the crowded, heavily regulated environment of initial teacher education, to establish and nurture the habit of RiP as an everyday practice of the professional teacher. The 'Towards concluding' section examines the potential of the Institute for Learning (IfL), and IfL's REfLECT communities, to support such endeavours.

\section{Critical pedagogy at a 'threshold moment'}

Why is this important now? The thinking behind this article has emerged in equal parts from the experience of working with and implementing the new statutory framework for teacher education in the Lifelong Learning Sector (LLS) encapsulated in Equipping our Teachers for the Future (DfES, 2004) and the combined experience of working with researching practitioners, as well as being researching practitioners ourselves.

It is possible to see Equipping our Teachers for the Future as a positive, threshold moment (Solar and Gillen, 2009) in post-compulsory education. Ideas about 'good' teaching and learning and what it means to teach and be a teacher in the sector are being reconfigured through the reshaping and remodelling of Initial Teacher Education and Continuing Professional Development. On the surface this new policy concern with the professional formation of teachers in the post-compulsory sector might be welcomed as long overdue attendance to the needs of an often over-looked 'Cinderella' workforce (TES, 1996; Randle and Brady, 1997; Hayes et al, 2007). This has been characterised since incorporation in 1992 by substantial variance in qualification levels, experience of teacher education, ideas about professional identity and experience of ongoing professional development.

However, a closer reading might draw attention to the limitations of the new framework and the implications of these for understanding ideas about professionalism within the sector.

On the one hand new baseline entitlements, notably expressed as requirements, to initial and ongoing teacher education have been embedded in statute. On the other, the articulation of these in practice by Lifelong Learning UK (LLUK), its subsidiary organisation Standards Verification UK (SVUK), and the IfL may serve to undermine potential for the growth of more expansive forms of professionalism. This can be seen to be particularly acute in the 
case of literacy, ESOL and numeracy teacher education where an additional layer of prescription around subject specialist knowledge adds to the complexity of how specialist teaching is framed.

Rather than a threshold moment in workforce reform, Equipping our Teachers for the Future (DfES, 2004) might be seen as evidence of an increasingly frantic impulse to regulate teacher education for the post-compulsory sector in response to both moral panics (Barton, 2000; Solar and Openshaw, 2002) and political concerns about skills deficits and economic productivity (Avis et al, 2003) and the perceived role of further education in closing 'skills gaps' (Foster, 2005).

Some commentators understand increasing regulation in the sector as symptomatic of a broader culture of compliance in relation to education. This culture seeks to 'discipline and to order struggles around what is taken for granted as "effective teaching" in relation to "pupil performance" and to "how all pupils should progress and what teachers should expect them to achieve"' (McDougall et al, 2006: p. 192) leading to an emphasis on the instrumental and performative over the social and political.

Rather than the 2004 imperative, McDougall et al (2006) recognise the 2001 policy shifts as a key moment of transition which saw the introduction of the FENTO standards and a range of compliance mechanisms, and began regulation of the sector through licensing processes known as 'endorsement' and 'approval'. In these terms Equipping our Teachers for the Future might be seen as the tightening of an already established stranglehold and the impact of this for teachers and teacher educators demands exploration.

\section{The impact of policy shifts on the teacher's role}

Drawing on Bernstein's ideas (2000), McDougall et al (2006) consider how the 2001 policy shifts re-situated literacy teachers and students and this offers a useful starting point for making sense of more recent policy moves. Bernstein proposed the notions of 'classification' and 'framing' to account for who is permitted to do what within the pedagogical context. Broadly 'classification' refers to the production of categories, how what is and what is not permitted in the educational context is determined, for example what is and what is not taught, who is and who is not allowed to teach it, who is and is not permitted to engage in different types of learning, and how differences between these categories (what is legitimate and what is not) are presented and enforced.

Whilst 'classification' accounts for the production of categories, 'framing' describes what happens within a category, for example how to teach the specified curriculum: 'the selection of the communication; its sequencing (what comes first, what comes second); its pacing (the rate of expected acquisition); the criteria' (Bernstein, 2000: p. 13).

Taking adult literacy education as an illustrative example, McDougall et al (2006) argue that the imposition of subject specifications for literacy teachers in 2002 changed the category of literacy education by newly determining what teachers must know and do, what 'counted' as legitimate knowledge and thereby also implicitly defining important, less legitimate knowledge. This re-positioned teacher educators and teachers from potential category definers able to exercise professional agency and judgment about what constituted the category of literacy education, to category implementers responsible for the framing within the already determined category i.e. the pace, ordering and style of teaching and learning.

Such a re-positioning of teachers signals an important shift in how the work of the teacher might be understood as the teacher's remit becomes not the 'what' but the 'how'. Thus the role of the teacher becomes technical, what Zukas and Malcolm (1999) call the 'psycho-diagnostician', concerned with how best to enable students to grasp that which 'needs' to be learned rather than to be reflexively and critically engaged with the social practices of learning. Within such a formula students are repositioned as 'learners' and student teachers more specifically as 'trainees' and the curriculum is, in Freire's (1987) sense, 'domesticated'.

This has significant implications for how we might see teachers as professionals. The professional autonomy, accountability to peers, tacit knowledge and pluralism, are the kinds of issues that Randle and Brady (1997: p. 232) note as being central to expansive forms of professionalism, are replaced. We see instead more managerial forms of educational practice to which teachers are subjected such as market control, unitarism and concerns with throughput and outputs or outcomes (ibid).

The changes we saw in 2004 shifted the landscape again. In 2001 teachers were re-positioned in relation to 'classification' policy changes. In 2004 they began to erode teachers' responsibilities in relation to 'framing'. The publication of mandatory 'Units of assessment' by LLUK (2007) prescribe much more precisely what must be assessed in addition to determining the pacing and sequencing of curricula for teacher education programmes restricting still further the scope of teacher decision making. Although we recognise, as has been argued by others, that classrooms continue to be sites of contestation and struggle we are persuaded by the arguments of Avis (2003) and Ecclestone (1999) that curricula so tightly controlled by specification of learning outcomes and units of assessment has the effect of minimising the impact of any such struggle or attempt at mediation. In these terms Equipping our Teachers for the Future may indeed represent a threshold moment for teachers in the post-compulsory sector. 


\section{$\mathrm{RiP}$ as critical pedagogy}

We contend that RiP chimes with ideas about the work of critical pedagogy which we see as especially significant in the current context. For us, critical pedagogy means committing to educational practices which acknowledge the social and political elements and provide dynamic, dialogic experiences for both teachers and students (Avis et al, 2003).

Following Zukas and Malcolm (1999) we argue for a concept of the teacher educator as a critical practitioner, a model that we see as antithetical to that being promoted today:

The educator as critical practitioner... adds a critical, social, political or ideological dimension on the process of reflection. In this sense it takes the process beyond the psychological and interpersonal, locating the practitioner in a social and, to varying degrees, political context.'

(1999: p. 2)

In this paradigm the 'locality' of expertise and the exercising of power within the classroom is less predictable than in traditional understandings. Relationships are more fluid and both teachers and learners may take up positions that are legitimately powerful or less powerful, expert or inexpert in relation to different domains and practices.

Kendall (2005) and Kendall and McDougall (2009 in press) have explored this dynamic in relation to teachers of literacy and media literacy noting that teachers are sometimes expert and sometimes not. Teachers do not and accept that they cannot, be 'expert' in every domain of literacy practice and are accepting of the limitations of 'teacher knowledge'. As such they are re-positioned as researchers within the field and acknowledge first, the literacy profiles of students and second, the possibility that learners may be expert in their life-world domains.

In turn, students may bring their own definitions about literacy to the classroom space and these may reflect their participation in 'non-schooled' specialist domains outside the classroom. Learners are recognised and acknowledged as experiencing functioning adult lives that involve participation in a variety of communities of practice. These in turn mediate literacies and texts. Teachers working within such a pedagogical context are challenged to read themselves, 'against the grain' (Street, 1999) as they reflexively explore their own expertise and inexpertise.

Within such a model, curricula might be conceived as a 'battleground for competing ideologies' (Kelly, 1999: p. 19) rather than as a given and the student invited to explore their disciplinary space as a diaspora of ideas about what knowledge should and might be:

'Curriculum - literally the course to be run - is not a given. There is no absolute, universally agreed curriculum. It is always a selection from a culture, a culture which is itself framed socio-historically. The curriculum - or should we say, a curriculum - is therefore always set within its socio-bistorical context. It is contingent upon, not "above", that context.'

(Hartley, 1997: p. 43)

Meaning/s become 'cultural and learned, but...also unfixed, sliding and plural...in consequence a matter for political debate... [whereby] culture itself is the limit of our knowledge: there is no available truth outside culture' (Belsey and Moore, 1989: $\mathrm{p}$. 10). This chimes with Bernstein's earlier analysis of subject knowledge through which he argues that the 'disorder' of knowledge is not revealed to students until very late in educational life (Bernstein, 1977: pp. 97-98).

A review of practitioner writing about RiP published in the field of adult literacy illustrates the gains for practitioners and strong resonance with the kinds of critical pedagogies we imagine here.

\section{Gains of RiP - for teachers and for their students}

Drawing on a range of literature about and by practitioners engaging in RiP in America, Australia, Canada and the UK we noted a number of important gains:

- practitioners making sense of their own personal and professional experience (Hamilton et al, 2007: p. 29)

- increased reflexivity about classroom practice that impacted on pedagogical decision making particularly in relation to understanding the significance of context (Docherty, 2006; Beebe, 2006)

- changing understandings of the meanings and uses of research, practitioner appetites for research and the role of students in the production of research (Hamilton et al, 2007); as well as the taking up of new positions as writers, particularly in relation to academic writing, and in relation to knowledge production

- practitioners were able to acknowledge their own drivers and motivations, including that of countering injustice (Herrington and Kendall, 2005).

Perhaps as significant to the claims of this article are the potential gains noted for and by the students of teachers engaged in RiP. Students are often represented as co-constructors of the meanings of research as they co-investigate and co-author (Herrington and Joseph, 2001; Roach and Goode, 1990) and perhaps begin in turn to share in the benefits reported above. In these terms particularly we argue, RiP offers a fruitful account of critical pedagogy in action.

Herrington (2008) has further noted the benefits of engagement with RiP over the career course. Using the term 'longitudinality' (Herrington, 2006 and 2008) Herrington pays attention to periods of time which extend beyond 
those involved in producing a single, individual piece of work and onwards through the time of building professional lives.

Through this lens the benefits of RiP are folded not only into the individual instances of RiP but into longer term thinking, as connections, meanings, consequences and outcomes shift to become differently pertinent over time. RiP is thus both shaped and shaping as the teachers come to know themselves, their research and their self in relation to research, differently over time.

\section{Towards concluding}

Where then does this take us? If, as we have argued, RiP might be seen as a process of critical pedagogy which is in turn an antidote to the limiting (for teachers and students) discourses of contemporary context of post-compulsory teacher education, it is then surely incumbent upon those with responsibility for professional education to carve out spaces for its enactment.

It is our contention that this must start at the Initial Teacher Education phase where the values, attitudes and habits of everyday practice are engendered. As we have shown, what we mean by this is that teachers are given the opportunity to engage in research about their work which has the potential to question, re-position and interrogate not simply the performative mechanics of classroom 'delivery' but also the social contexts within which classroom teaching occurs.

We challenge teacher educators to make RiP the starting point for curriculum planning so that attendance to creating space for such work becomes the priority for curriculum design rather than something for which space is snatched and cleaved only after statutory requirements have been fulfilled. We realise that this requires a bold kind of confidence but maintain that any associated risk is far outweighed by the kinds of benefits enjoyed by individuals and communities noted above.

We wonder aloud whether the IfL REfLECT tool offers the potential to minimise perceived risks for teacher educators and to nurture and sustain communities of critical practitioners. Evidence from educators using the same technology in local settings (see Hughes 2008a, 2008b) is hugely encouraging. At the time of writing the jury is still out for many teacher educators about IfL but Hughes' creative, carefully theorised work suggests that thoughtful attendance to the possibilities of REfLECT might indeed yield the opportunities for the kind of longitudinal gains Herrington notes. Perhaps after all, the ball is not yet entirely out of our court?

We invite further discussion of the challenges and possibilities of embedding RiP into teacher education programmes and signpost this as a key area for experimentation and research. The time is surely right, in the third year of the new programmes and when our relationship with the processes and practicalities of endorsement is 'maturing', for increased experimentation and risk taking. How far and in what respects, does RiP enable teachers and teacher educators to transgress policy imposed constraints and what are the longer term benefits (to teachers and students) of establishing a RiP as an everyday habit of professional practice?

\section{References}

Avis, J., Bathmaker, A., Kendall, A. (2003) 'Conundrums of our own making: critical pedagogy and trainee further education teachers', Teacher Development Vol. 7, pp. 191-209. http://dx.doi.org/10.1080/13664530300200198

Barton, D. (2000) Moral panics about literacy. Lancaster University Centre for Language in Social Life, Working Paper Series: http://ling.lancs.ac.uk/pubs/clsl/wpapers.htm [accessed 2nd Sept 2004].

Beebe, L. (2006) 'From Concrete to Abstract: The Benefits of Using a Guided Reflective Writing Technique with Adult Literacy Students Research in Practice Projects RIPAL-BC', in Horsman, J., Woodrow, H. (eds.) Focused on Practice. A Framework for Adult Literacy Work in Canada. Vancouver: Literacy BC.

Belsey, C., Moore, J. (1989) The Feminist Reader: Essays In Gender And The Politics Of Literary Criticism. Basingstoke, Hampshire: Macmillan.

Bernstein, B. (2000). Pedagogy, Symbolic Control and Identity. Theory, Research, Critique. Oxford: Rowman and Littlefield Publishers Inc.

Bernstein, B. (1977) Class, Codes And Control Vol.3, Towards A Theory Of Educational Transmissions. London: Routledge, Kegan and Paul.

Docherty, A. (2006) 'Catching Our Breath: Collaborative Reflection-on-Action in Remote Rural BC. Research in Practice Projects RIPAL-BC', in Horsman, J., Woodrow, H. (ed.) Focused on Practice. A Framework. for Adult Literacy Work in Canada. Vancouver: Literacy BC.

DfES (2004) Equipping our Teachers for the Future. London: DfES.

Ecclestone, K. (1999) 'Ensnaring Or Empowering? The Implications Of Outcome Based Assessment In Higher Education', Higher Education Quarterly Vol. 53, No. 1, pp. 29-49. http://dx.doi.org/10.1111/1468-2273.00111

Foster, A. (2005) Realising The Potential: A Review Of The Future Role Of Further Education Colleges. London: DIUS.

Freire, P. (1987) A Pedagogy Of Liberation - Dialogues For Transforming Education. Basingstoke, Hampshire: Macmillan

Hamilton, M. (2006) Practitioner Research: Just a Fling or a Long-term Relationship? REFLECT Issue 6, pp. 14-18. London: NRDC.

Hamilton, M., Davies, P., James, K. (2007) Practitioners Leading Research. A Report of action research projects for the NRDC Practitioner led Research Initiative (PLRI). London: NRDC.

Hartley, D. (1997) Reschooling Society. London: Falmer Press.

Hayes, D., Marshall, T., Turner, A. (2007) A Lecturer's Guide to Further Education. Berkshire, England: OUP.

Herrington, M. \& Joseph, T. (2001) 'Literacies within Prison Settings: A Fourth Space?' RaPAL Bulletin Vol. 43, Spring, pp. 18-22.

Herrington, M. \& Kendall, A. (2005) Insights from Research and Practice. Leicester: NIACE. 
Herrington, M. (2006) A Practitioner Researcher Project Working with the Adult Literacy Curriculum: A Case Study from the Black Country Colleges. Final Report to LSC. University of Wolverhampton, School of Education.

Herrington, M. (2007) Research in Practice as a Means of Professional Development in Adult Literacy Education: Literacies, Dyslexia and the Construction of Practitioner Knowledge. A Longitudinal Case Study 1985-2006 (unpublished PhD), University of Nottingham.

Herrington, M. (2008) 'Research in Practice in Adult Literacy: What does a Longitudinal Model look like?', http://www.nald.ca/litweb/province/ab/ripal/online.htm [accessed $1^{\text {st }}$ June 2009].

Horsman, J., Woodrow, H. (2006) (eds.) Focused on Practice. A Framework for Adult Literacy Work in Canada. Vancouver: Literacy BC.

Hughes, J. (2008a) 'Letting In The Trojan Mouse: Using An E-Portfolio System To Rethink Pedagogy'. ASCILITE Melbourne Australia conference proceedings.

Hughes, J. (2008b) 'E-portfolio-Based Learning: A Practitioner Perspective', Enhancing Learning in the Social Sciences Vol. 1, No. 2. http://www.eliss.org.uk/PreviousEditions/Volume1Issue2/ Abstracts/tabid/73/Default.aspx [accessed 1st June 2009].

Kelly, A. V. (1999) The Curriculum: Theory And Practice. London: Paul Chapman.

Kendall, A. (2005) Reading fictions: reading reader identities in Black. Country further education communities. (unpublished PhD), University of Birmingham.

Kendall, A., McDougall, J. (2009 in press) 'Just Gaming: On Being Differently Literate' E-ludamos: Journal for Computer Game Culture

LLUK (2007) 'Guidance For Awarding Institutions On Teacher Roles And Initial Teaching Qualifications. All Mandatory Units Of Assessment' http://www.lluk.org/documents/uoa_all.pdf [accessed 24 ${ }^{\text {th }}$ Sept 2009].

McDougall, J., Walker, S., Kendall, A. (2006). 'Shaping Up? Three Acts Of Education Studies As Textual Critique' International Studies in Sociology of Education Vol. 16, No. 2 (September) pp. 159-173. http://dx.doi.org/10.1080/09620210600849877

Randle, K., Brady, N. (1997) 'Managerialism and Professionalism in the 'Cinderella Service', Journal of Vocational Education and Training, Vol. 49, No. 1, pp. 121-139. http://dx.doi.org/10.1080/13636829700200007

Roach, D., Goode, P. (1990) 'New Writers Research Their Own Writing Processes' in Herrington, M. , Kendall, A. (eds) Insights from Research and Practice. Leicester: NIACE.

Solar, J., Gillen, J. (2009) ‘A Threshold Moment For Virtual Worlds’, United Kingdom Literacy Association Conference, Greenwich University, July 2009.

Solar, J., Openshaw, R. (2002) 'Literacy Crisis And Reading Policy In England And New Zealand', BERA Conference, Exeter University, September 2002.

Street, B. (1999) 'The Implications of the 'New Literacy Studies' for Literacy Education', English in Education Vol. 31 , No 3. http://dx.doi.org/10.1111/j.1754-8845.1997.tb00133.x

TES (1996) 'Cinderella Sector Faces Even Fewer Peanuts 1996’ http://www.tes.co.uk/ article.aspx?storycode=110309 [accessed 20th July 09].

Winter, R. (1989) Learning from Experience: Principles and Practice in Action Research. Lewes: Falmer.

Zukas, M., Malcolm, J. (1999) 'Models Of The Educator In Higher Education', British Educational Research Association Conference, University of Sussex, 2-5 ${ }^{\text {th }}$ September, http://www.leeds.ac.uk/ educol [accessed June 25th 2004]. 